Mark T. Milen · David A. Bloom

J. Culligan $\cdot$ K. Murasko

\title{
Albert Adamkiewicz (1850-1921) - his artery and its significance for the retroperitoneal surgeon
}

\begin{abstract}
The artery of Adamkiewicz is an important retroperitoneal vessel that is chiefly responsible for vascularization of the lumbar enlargement of the lower spinal cord. The significance of this artery, named after Albert Adamkiewicz, a talented Polish pathologist known for his pioneering work on spinal anatomy and physiology, has not been widely recognized. It is a useful landmark among the numerous blood vessels that nourish the spine. Injury to the artery of Adamkiewicz can result in devastating ischemia of the lower spinal cord.
\end{abstract}

Eponyms are useful tools that enrich memory, a process sorely taxed by the proliferation of words and information in modern medicine. The beauty of an eponym is that it enlivens scientific discourse by adding personality and historical perspective to otherwise bland terminology. The most durable eponyms are those attached to structures, processes, and disorders of clinical significance. The historical roots of many eponyms become lost over time and bear recapitulation for each new generation of practitioners. Such is the case for the artery of Adamkiewicz.

The artery of Adamkiewicz was an interesting anatomical finding when first elucidated over 100 years ago, but its practical significance was minimal. Clinical relevance had to await the present century, when major thoracic and abdominal surgical procedures became commonplace in surgical subspecialties encompassing aortic replacement, retroperitoneal lymph node dissection, and anterior-posterior spinal fusion. The retroperitoneum is particularly important terrain for the genitourinary surgeon, whether accessed conventionally,

M. T. Milen $(\bowtie) \cdot$ D. A. Bloom · J. Culligan · K. Murasko

Department of Urology,

University of Michigan,

1500 East Medical Center Drive,

Ann Arbor, MI 48019-0330, USA laparoscopically, or percutaneously. The artery of Adamkiewicz is a critical landmark for the retroperitoneal surgeon and a good segue for a review of spinal cord vascularity.

\section{Albert Adamkiewicz}

Albert Wojciech Adamkiewicz was born to a family of physicians on August 11, 1850, in Zerkow, a city located in Poznan Duchy of imperial Poland. He began his formal education in Krolewiec, also known as Konigsberg or, presently, Kaliningrad, in western Russia. A city with a rich intellectual history, this was the birthplace and early home of the great Enlightenment philosopher Immanuel Kant (1724-1804). Adamkiewicz continued his studies in Wroclaw (Vratislavia), one of the oldest towns in Poland, and he graduated from medical school in Würzburg, Bavaria. This prestigious academic center was famous for its paper industry, scientific instruments, and the historic Julius Hospital, founded in 1576 and named after Prince Bishop Julius Echter (1545-1617). This would later become the university at which Wilhelm Conrad Roentgen would discover X-rays in 1895.

Adamkiewicz specialized in surgery and obstetrics and continued living in Würzburg until 1876. He worked in the department of physiology and internal diseases and quickly advanced to assistant professor in physiology [1]. At 26 years of age, Adamkiewicz moved to Berlin as a senior physician at the nervous diseases ward of the Charite Hospital, where he obtained an assistant professor degree in pathology. Returning to Krakow in his native Poland, Adamkiewicz was appointed to the chair of the general and experimental pathology department at the Jagiellonian University in 1880. This was the second oldest university in eastern Europe, having been established in 1364 by Kazimierz Jagiellonian III, the Great King of Poland (1309-1370), and recognized for its excellent medical and pharmaceutical programs. In 1893, at 43 years of age, Adamkiewicz relocated to Vienna as head of a ward at the Rotschyld 
Hospital. His particular interests in pathology included oncology and the analysis of the nervous system. Adamkiewicz became known for his pioneering work on the spinal cord vascularization. His monograph, On spinal cord vascularization, published in 1881, was the first comprehensive treatise on the subject and provided the definitive description of the artery that came to be associated with his name [2]. Independent work published 7 years later by Henryk Kadyi hinted at some professional jealousies in the unraveling of spinal cord vascularity but clearly established Adamkiewicz's priority [9]. Adamkiewicz maintained active memberships in various prestigious professional societies, including the Anatomical Society of Leipzig (central Germany). He spent his last years in Vienna. A photograph shows him looking distinguished and quite bald, with a prominent walrus mustache [6]. He died on October 31, 1921.

\section{Spinal cord vascularity and the artery of Adamkiewicz}

The spinal cord is supplied by three longitudinally oriented arteries: a single anterior spinal artery, formed rostrally from the junction of two anterior spinal branches that come from the vertebral arteries, descends in the anterior median fissure; two posterior spinal arteries also derive from the intracranial vertebral artery, although a little lower than the origins of the branches that form the anterior spinal artery, and descend along the posterolateral sulci of the cord. All along the way down the spinal cord, the three major arteries pick up segmental anterior and posterior radicular feeder arteries that enter at the intervertebral foramina with the nerve roots. Additionally, at certain vertebral levels, medullary feeder branches arise from segmental spinal arteries to join the three longitudinal spinal arteries and enhance the cord circulation. On average there are 8 anterior medullary feeders and at least 12 posterior medullary feeder arteries [4]. Adamkiewicz identified the largest and most important of all of these and described an anastomosing system around the spinal cord that he called the "vasocorona," or vascular crown.

The artery of Adamkiewicz is a unilateral anterior radicular artery of the spinal cord that is known as the great anterior medullary artery. Although it is called a unilateral anterior radicular artery, it is distinct from the true dorsal and ventral radicular branches that nourish the nerve roots at every level, coming off each segmental spinal vessel after entering into each intervertebral foramen bilaterally. Also called the artery of the lumbar enlargement, the artery of Adamkiewicz is appreciably larger (1.0-1.3 cm in diameter) than the other anterior radicular arteries of the spinal cord. Most frequently it travels with a lower thoracic or upper lumbar spinal root from the left side. In about $80 \%$ of patients it enters the spinal canal from the left at a variable level between $\mathrm{T} 8$ and L4. A study by Lazorthes et al. [7] found the artery of Adamkiewicz between T9 and T12 in $74 \%$ of cases, at L1-L2 in $10 \%$, and at T5-T8 in $15 \%$ of cases. An ascending branch and anastomoses to the posterior arteries are present.

\section{Clinical significance of the artery of Adamkiewicz}

The low thoracic/high lumbar region has a greater distance between radicular arteries than do the higher levels of the spinal cord. In addition, the intercostal arteries of this area do not interconnect with other arteries with the extensive rete of vessels seen in the cervical and lumbosacral regions. Spinal cord infarction secondary to occlusion of the artery of Adamkiewicz can occur on direct injury to the spine or spinal cord in this more vulnerable location.

Fortunately, the dependence on this artery is not absolute. In 1970, Dichiro et al. [5] found that this artery could be ligated in rhesus monkeys without complication but that paraplegia would result if the anterior spinal artery were simultaneously occluded. It has been suggested that the paraplegia related to thoracic aortic surgery is related to cross-clamping that occludes the segmental vessels bilaterally. The anterior spinal artery in the T4-T9 region is quite small and is also susceptible to injury during anterior spinal operative procedures. This combination of anatomical considerations makes the lower thoracic and upper lumbar spinal cord somewhat at risk for infarction when there is significant vascular manipulation. Even relatively minor challenges, such as umbilical artery catheterization, can produce spasm of embolism to the artery of Adamkiewicz [8]. Spinal cord infarction in this area is devastating, resulting in paraplegia, colonic ischemia, major sensory deficits, gluteal necrosis, and loss of bowel and bladder control. The genitourinary surgeon needs to understand retroperitoneal anatomy, which includes the spinal cord and its vascular nuances.

\section{Conclusion}

Time's arrow removes each generation of physicians from the denouements that create the corpus of medical science. Unless we purposefully refresh ourselves by restudying those denouement and eponyms, the meaning and value of our terminology diminishes. In some instances an anatomical finding achieves clinical significance only with the expansion of the surgical armamentarium, such as with the medical umbilical ligament, which is now a key landmark in genitourinary laparoscopy [3]. Similarly, the artery of Adamkiewicz was one small denouement a century ago but is now a critical structure for the modern retroperitoneal surgeon. 


\section{References}

1. Herman E (1968) Albert Wojciech Adamkiewicz. Neuropatol Pol 1: 1-10

2. Adamkiewicz A (1881) Die Blutgefässe des menschlichen Rückenmarkes - I. Theil. Die Gefässe der Rückenmarksubstanz. Sitzungsber Dtsch Akad Wiss Wien Math Naturwiss Kl LXXXXIV

3. Bloom DA, Guiney EJ, Ritchey ML (1994) Normal and abnormal pelviscopic anatomy at the internal inguinal ring in boys and the vasal triangle. Urology 44: 905-908

4. Clemente CD (1985) In: Gray H (ed) Anatomy of the human body, 30th American edn. Lea and Febiger, Philadelphia, p 964-971
5. DiChiro G, Fried LC, Doppman JL (1970) Experimental spinal cord angiography. Br J Radiol 43: 19-30

6. Djindjian R, Hurth M, Houdard R (1971) En hommage a Albert Wojceiech Adamkiewicz (1850-1921): etude arteriographique normal et pathologique de l'arteria radicularis anterior magna. Rev Neurol (Paris) 5: 211-218

7. Lazorthes G, Gouaze A, Zadeh JO, et al (1971) Arterial vascularization of the spinal cord: recent studies of the anastomotic substitution pathways. J Neurosurg 35: 253-262

8. Munoz ME, Roche C, Escriba R, Martinez-Bermejo A, Pascual-Castroviejo I (1993) Flaccid paraplegia as complication of umbilical artery catheterization. Pediatr Neurol 9: 401-403

9. Sokolowska-Pituchowa J (1980) Two monographs on the spinal cord vascularization. Folia Morphol (Warsz) 39: 1-8 